\title{
Diagnostic value of active protraction and retraction for sternoclavicular joint pain
}

\author{
Alexander Van Tongel ${ }^{1 *}$, Anne Karelse ${ }^{1,3}$, Bart Berghs $^{2}$, Tom Van Isacker $^{4}$ and Lieven De Wilde ${ }^{1}$
}

\begin{abstract}
Background: Sternoclavicular joint (SCJ) arthropathy is an uncommon cause of mechanical pain. The aim of this study is to evaluate the diagnostic value of two active clinical tests for localizing the sternoclavicular joint as the source of mechanical pain.

Methods: All patients between June 2011 and October 2013 that visited the orthopedic departments of three hospitals with atraumatic pain in the area of the SC joint were evaluated. Local swelling, pain at palpation, pain during arm elevation and two newly described tests (pain during active scapular protraction and retraction) were evaluated. CT images were evaluated. The patients were then divided into two groups according to whether they had a $\geq 50 \%$ decrease in pain following the SCJ injection. Sensitivity and specificity for local swelling, the four clinical tests and CT-scan were measured.
\end{abstract}

Results: Forty eight patients were included in this study and SC joint pain was confirmed in 44. The tests with highest sensitivity were pain on palpation, (93\% sensitivity) and pain during active scapular protraction (86\%). CT-scan showed a sensitivity of $84 \%$. Local swelling showed a high specificity (100\%).

Conclusion: Pain at the SCJ during active scapular protraction is a good clinical diagnostic tool for SC arthropathy.

Keywords: Clinical test, Sternoclavicular, Arthopathy, Sensitivity, Specificity, Scapular protraction

\section{Background}

Joint pain (pain localized in the area of a joint) is clinically reproducible by pain provocation tests, and, ideally, is completely relieved by infiltration of the symptomatic joint with local anesthetics. Sternoclavicular joint (SCJ) pain is uncommon but the joint is subject to the same disease processes that occur in other joints.

Arthritis is the most common nontraumatic disease of the SCJ. The most frequent types of arthritic illnesses include post-traumatic, septic, inflammatory seropositive (rheumatoid arthritis), seronegative (ankylosing spondylitis, Reiter syndrome, colitic, and psoriatic), and crystal (gout, pseudogout). Other less common SCJ-specific arthritides include Friedrich disease, condensing osteitis, SAPHO (synovitis, acne, pustulosis, hyperostosis, and osteitis), and palmoplantar pustulosis. Neoplasms involving the SCJ include primary tumors, such as Ewing

\footnotetext{
* Correspondence: Alexander.vantongel@uzgent.be

${ }^{1}$ Department of Orthopaedic Surgery and Traumatology, Ghent University

Hospital, De Pintelaan 185, B-9000 Gent, Belgium

Full list of author information is available at the end of the article
}

sarcoma, and secondary neoplasm, such as squamous cell carcinoma and adenocarcinoma [1].

Patients are mostly seen for consultation because of localized swelling and/or mechanical pain at the level of the SCJ [2-4]. However, pathology of the SCJ can also cause referred pain to areas distant from the joint. These area includes the anterior trapezial fold, along the lateral clavicle to the anterior shoulder, the neck and jaw and it can overlap the pain pattern of those of the acromioclavicular (AC) joint, the subacromial space and cervical nerves [5-7].

The most common used imaging technique to evaluate SCJ pathology is computertomography (CT) [8-10]. The sensitivity of local swelling and pain during palpation at the SCJ has been evaluated [1]. But in contrast to commonly described active tests of the shoulder girdle [11-14], to our knowledge, no active clinical tests of the joint has not been evaluated. The aim of this study is to evaluate the diagnostic value of two newly described active clinical test for localizing the SCJ as cause of the mechanical pain. 


\section{Methods}

All patients that visited the orthopedics departments of three hospitals between June 2011 and June 2013 with a history of atraumatic pain in the area of the SC joint were included in this retrospective study.

Exclusion criteria were as follows: previous SC surgery, (2) atraumatic SC instability, (3) previous or known allergies to lidocaine and (4) refusal of a reference standard injection lidocaine test. Age, sex, hand dominance, affected arm, onset and duration of pain are documented.

All patients were examined bilaterally in upright and supine position using a standard protocol. This included inspection and clinical examination of the neck and shoulder region. Also signs of palmar and plantar pustulosis, acne or infection typical of palmoplantar pustulosis, SAPHO syndrome, and septic arthritis were evaluated. Local swelling of the SCJ and pain on palpation of the SCJ and ACJ. Active and passive range of motion of the neck were measured. With regard to the shoulder, active and passive forward flexion, abduction, internal and external rotations were measured by visual estimation. If active flexion above $100^{\circ}$ was painful at the SC joint area, the test was positive. Next the patient was asked to actively perform maximal protraction and retraction of the shoulder girdle in an upright position and pain during these tests was evaluated (Figures 1 and 2).

\section{Imaging studies}

All patients were positioned in the CT gantry according to a previously described method, that is in dorsal recumbency, with a cushion on the belly and a strap around the body and this cushion, to keep the arm adducted in the coronal plane and the forearm flexed in the sagittal plane of the body [15]. This standardized position mimics a reproducible surgical position and minimizes positional errors. All sternoclavicular joints were examined with CT scans with following settings: Somatom Volume Zoom Siemens (Siemens Business Park, Marie Curiesquare 30 Square Marie Curie 30; 1070 Brussel - Bruxelles) ; matrix: 512/ kV:140/ eff. mAs: 350. The scan field of view (SFOV) was always 500. Radiographic parameters of rheumatoid or osteoarthritis (bone cyst, osteophytes, narrowing of the
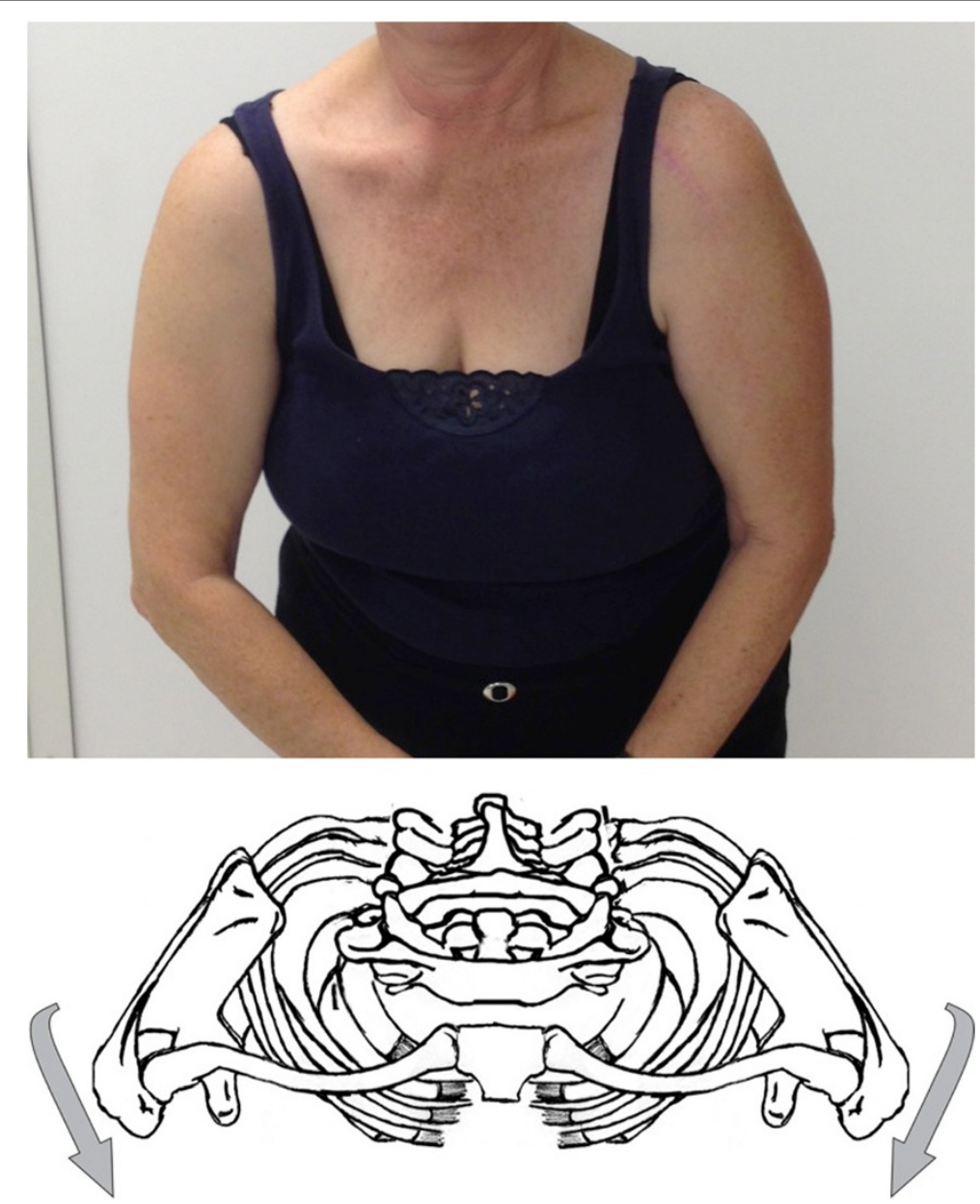

Figure 1 Active scapular protraction. 


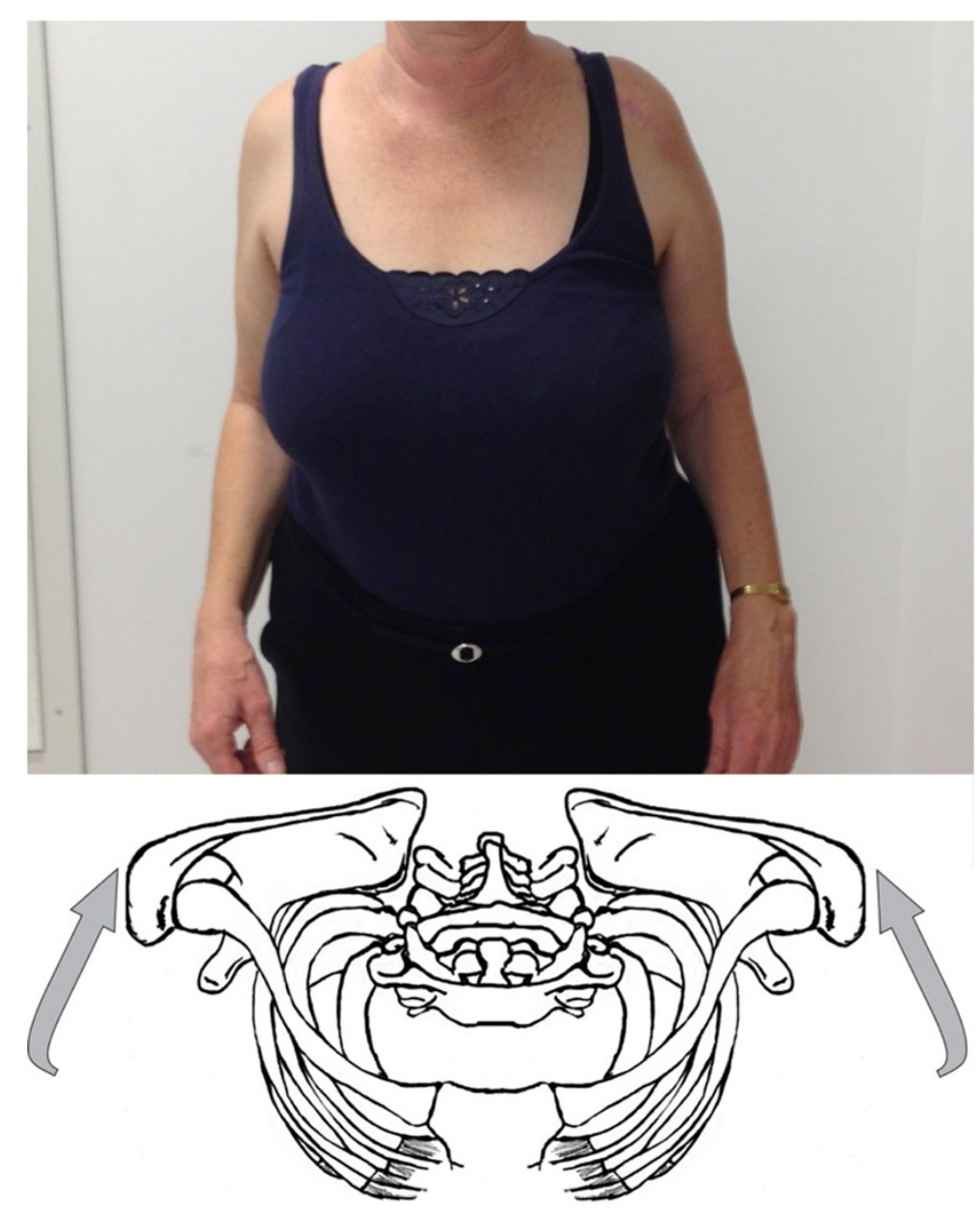

Figure 2 Active scapular retraction.

joint space, anterior subluxation), hyperostosis of the sternum, clavicles, and upper ribs (sternocostoclavicular hyperostosis $(\mathrm{SCCH})$ ), obliteration of the marrow space (condensing osteitis), irregularity of SCJ with bony destruction of medial end of clavicle (friederich disease) or joint effusion, bone and cartilage erosions, gas within the joint, and soft tissue swelling (septic arthritis) or no abnormality were checked on the CT.

\section{Reference test standard}

The reference test standard was an ultrasound guided SCJ infiltration, of $1 \mathrm{~mL}$ of $2 \%(\mathrm{v} / \mathrm{v})$ lidocaine [16]. All patients with pain in the sternoclavicular area were injected by an experienced orthopaedic surgeon (i.e., one of the authors). Patients sensing alleviation of pain with $50 \%$ or more, within ten minutes after the lidocaine injection, were considered to have SCJ pain; i.e., they have a positive reference test standard. Patients with less than 50\% pain relief were considered to not have SCJ pain [17]. If there was a positive reference test is an ultrasound guided SCJ infiltration of $1 \mathrm{~mL}$ (40 mg) of methylprednisolone [16,18] was given.
If no abnormality was found on CT but the patient had a positive reference standard test, the the pathology was called monoarthritis e causa ignota.

\section{Statistical analysis}

Sensitivity, specificity, positive and negative predictive values of the clinical diagnostic tests were determined with the methods described by Sackett et al. [19].

This study was approved by the appropriate ethics committee (UZ Ghent, Chairman: Prof. Dr.Rubens Registration number: B670201317780).

\section{Results}

\section{Patient demographics}

Between June 2011 and June 2013, 48 patients with unilateral atraumatic pain in the area of the SC who met our inclusion criteria were enrolled in this study (Table 1).

There were 9 men and 39 women, with an average age of 60 years, ranging from 23 to 74 years. Forty-one patients were right-handed and the dominant shoulder was involved in 40, while the nondominant arm was affected 
Table 1 Sensitivity, specificity and predictive value of clinical and imaging test

\begin{tabular}{lllll}
\hline & Sensitivity & Specificity & $\begin{array}{l}\text { Positive } \\
\text { predictive } \\
\text { value }\end{array}$ & $\begin{array}{l}\text { Negative } \\
\text { predictive } \\
\text { value }\end{array}$ \\
\hline Tenderness & $93 \%$ & $25 \%$ & $93 \%$ & $25 \%$ \\
$\begin{array}{l}\text { Prominence } \\
\text { Pain active }\end{array}$ & $61 \%$ & $100 \%$ & $100 \%$ & $0 \%$ \\
protraction (N) & $86 \%$ & $50 \%$ & $95 \%$ & $25 \%$ \\
$\begin{array}{l}\text { Pain active retraction (N) } \\
\text { Pain active elevation }\end{array}$ & $85 \%$ & $75 \%$ & $95 \%$ & $11 \%$ \\
CT & $84 \%$ & $50 \%$ & $93 \%$ & $14 \%$ \\
\hline
\end{tabular}

in 8. All patients reported an insidious onset of symptoms. Average duration of symptoms was 11 months (range, 3-24).

\section{Sternoclavicular arthropathy}

Forty-four patients were confirmed to have SCJ abnormality by their response to the SCJ injection. Thus, the prevalence of SCJ abnormality in this patient population was $90 \%$. This high prevalence indicates that mechanical pain in the area of the sternoclavicular region is itself a reliable sign for SCJ arthropathy. Four patients had no relief of pain after the injection.

These positive and negative (control) groups were compared with regard to their responses to the clinical and imaging tests.

The most sensitive clinical test for identifying SCJ arthropathy was examination for local SCJ tenderness (93\% sensitivity), followed by the pain during active protraction (86\%). CT showed a sensitivity of $84 \%$ (Table 1 ). Four different pathologies were diagnosed (Table 2) (Figure 3).

\section{Discussion}

SC arthropathy is an uncommon cause of pain. The location of pain originating from the $\mathrm{SC}$ joint can be diverse and patients are often not able to identify the exact location. As stated by Hassett et al., the pain pattern can overlap those of the $\mathrm{AC}$ joint, the subacromial space and cervical nerves. Hence, SC joint pain needs to be considered in the differential diagnosis of pain from these structures and their referred anatomical site [6].

Table 2 Different diagnosis of sternoclavicular arthropathy

\begin{tabular}{lc}
\hline Diagnosis & Number of patients \\
\hline Degenerative arthritis & 33 \\
SCCH & 2 \\
Freiderich disease & 2 \\
Monoarthtritis e cause ignota & 7 \\
\hline
\end{tabular}

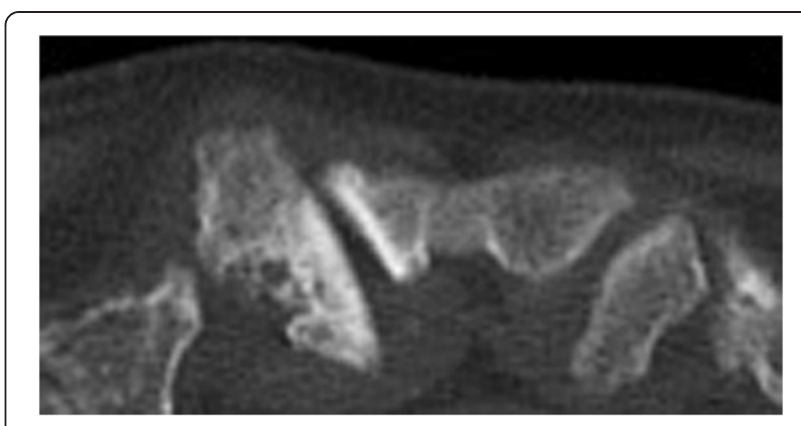

Figure 3 Axial CT image in patients with symptomatic degenerative $\mathrm{SC}$ arthritis.

But because of its rarity, accurate diagnosis is often delayed. Easy clinical tests of the joint that can be included in the normal shoulder exam could help to obtain a sooner diagnosis and treatment for patients with SC arthropathy.

Three clinical signs for SC arthropathy have previously been described in the literature: tenderness by palpation, a local swelling and pain during active elevation [20-23]. In our study, local tenderness was the most sensitive test for SC arthropathy (93\%). Also, in patients with transient SC arthropathy, tenderness was also a common finding (84\%) [1]. In our population, local swelling was most commonly seen in patients with signs of degenerative arthritis on CT. This correlated with the findings of Van Tongel et al. who described an anterior subluxation of the clavicle in patients with symptomatic degenerative arthritis [24]. This hard prominence is in contrast with the temporary local swelling in patients with transient SC arthropathy without any signs of degeneration [1].

The high specificity of clavicular prominence for SC pathology in our population is probably not correct because, for example, bone tumors also can be a cause of prominence of the medial clavicle; however, we did not see those patients in our clinic.

Pain in the SC region during arm elevation above $100^{\circ}$ showed a high sensitivity (84\%). But a problem with this test is that it requires the combined motion of the SC, $\mathrm{AC}$, glenohumeral, and scapulothoracic joints. This means that in some cases of glenohumeral pathology (frozen shoulder, pseudoparalysis) this test cannot be used. This is a reason why we described the active scapular protraction and retraction. In our opinion, this motion tries to isolate the $\mathrm{SC}$ motion as much as possible. Inman et al. described that during scapular protraction and retraction of the shoulders, no appreciable motion occurs at the AC joint or any great rotation of the clavicle. He stated that scapular protraction and retraction is occurring predominantly at the SCJ [25]. Abott et al. described that during retraction and protraction of the shoulder the scapula describes an arc of 50 degrees around the SCJ. In the average 
individual the clavicular motion is 35 degrees at the $\mathrm{SCJ}$ and scapular movement at the AC joint accounts for 15 degrees [26]. By performing active scapular protraction and retraction the motion at the glenohumeral joint and the $\mathrm{AC}$ joint is minimized.

Anatomical study of the SCJ showed that the articular surface of the clavicle is located antero-inferiorly [27]. This means active scapular protraction creates a compression and active scapular retraction a distraction of the joint.

Scapular protraction showed a high sensitivity (91\%) in contrast to scapular retraction (39\%). Similar to the clinical test for the $\mathrm{AC}$ joint it seems that compression of the SC joint is more sensitive to diagnose SC arthropathy than distraction [28].

The most commonly used technical investigation to evaluate the SCJ is CT-scan. CT imaging has been described to be superior to other imaging techniques when evaluating narrowing of the joint space, osteophytes, subchondral sclerosis, and cysts at both sides of the joint $[3-5,21,29]$. Conventional plain $x$-rays of the joint may be suboptimal to evaluate abnormalities because the overlying ribs, spinal column, and soft-tissue obscure joint detail [30]. MRI should be the first modality of choice when suspecting malignancies or infection in the $\mathrm{SC}$ region, but not for the diagnosis of degenerative osteoarthritis [31]. Scintigraphy is a sensitive method for detecting disorders with increased bone turnover, but is in general not specific for disorders in the SC region except for the "bullheadlike" sign in sternocostoclavicular hyperostosis [31].

In $86 \%$ of our cases, CT showed pathological changes. In $14 \%$ no pathology was seen on CT scan. Two weeks after the infiltration, these patients were asymptomatic and no further technical investigation was performed. These patients were diagnosed with a mono-arthritis e causa ignota.

This study is unique because, to our knowledge, no one has previously described active isolated thoracoscapular to evaluate SC arthropathy. This is also the first time the values of different tests used to diagnose SCJ pain is evaluated. Our study also has several weaknesses. First, the study group consisted of a relatively small number of patients who fulfilled the inclusion criteria. Second, several other causes of SC arthropathy (seronegative spondyloarthropathie, septic arthritis, rheumatoid artritis) were not seen in our patient population.

\section{Conclusion}

Pain during active scapular protraction is an easy clinical test that can be a good clinical diagnostic tool for sternoclavicular arthopathy

\section{Consent}

Written informed consent was obtained from the patient for the publication of this report and any accompanying images.

\section{Abbreviations \\ SC: Sternoclavicular; SCJ: Sternoclavicular joint; CT: Computertomography; AC: Acromioclavicular.}

\section{Competing interests}

The authors declare that they have no competing interests.

\section{Authors' contributions}

AVT and LDW included patients in the study and wrote the article. BB, AK $\mathrm{TV}$ included patients in the study. All authors read and approved the final manuscript.

\section{Acknowledgements}

I want to thank Sheila McRae (PanAm clinic) for her linguistic support.

\section{Author details}

'Department of Orthopaedic Surgery and Traumatology, Ghent University Hospital, De Pintelaan 185, B-9000 Gent, Belgium. ²Department of Orthopaedics and Traumatology, Upper Limb Unit, AZ Sint-Jan AV Brugge Oostende, Campus Brugge, Ruddershove 1, B-8000 Brugge, Belgium. ${ }^{3}$ Department of Orthopaedics and Traumatology, Zorgsaam Terneuzen Wielingenlaan 2, 4535 PA Terneuzen, The Netherlands. ${ }^{4}$ Department of Orthopaedics and Traumatology, AZ Sint-Lucas Brugge, Sint Lucaslaan 29, B 8310 Brugge, Belgium.

Received: 28 October 2014 Accepted: 1 December 2014 Published: 11 December 2014

\section{References}

1. Sternheim A, Chechik O, Freedman Y, Steinberg EL: Transient sternoclavicular joint arthropathy, a self-limited disease. J Shoulder Elbow Surg 2014, 23(4):548-552.

2. Westermann H: Die Erkrankungen der Sternoklavikulargelenke mit besonderer Berücksichtigung der Arthrosis deformans. Arch Klin Chir 1942, 203:19-42.

3. Kowallik B: Arthrosis deformans of the sternoclavicular joint. Zentralb/ Chir 1951, 76(10):672.

4. Bonola A, Mastragostino S: Arthritis deformans of the sterno-costo-clavicular joint. Reumatismo 1954, 6(6):333.

5. Yood RA, Goldenberg DL: Sternoclavicular joint arthritis. Arthritis Rheum 1980, 23(2):232-239

6. Hassett G, Barnsley L: Pain referral from the sternoclavicular joint: a study in normal volunteers. Rheumatology 2001, 40(8):859-862.

7. McConaghy JR, Oza RS: Outpatient diagnosis of acute chest pain in adults. Am Fam Physician 2013, 87(3):177-182.

8. Kier R, Wain SL, Apple J, Martinez S: Osteoarthritis of the sternoclavicular joint. Radiographic features and pathologic correlation. Investig Radiol 1986, 21(3):227-233.

9. Destouet JM, Gilula LA, Murphy WA, Sagel SS: Computed tomography of the sternoclavicular joint and sternum. Radiology 1981, 138(1):123-128.

10. Restrepo CS, Martinez S, Lemos DF, Washington L, McAdams HP, Vargas D, Lemos JA, Carrillo JA, Diethelm L: Imaging appearances of the sternum and sternoclavicular joints. Radiographics 2009, 29(3):839-859.

11. O'Brien SJ, Pagnani MJ, Fealy S, McGlynn SR, Wilson JB: The active compression test: a new and effective test for diagnosing labral tears and acromioclavicular joint abnormality. Am J Sports Med 1998, 26(5):610-613.

12. Hermans J, Luime JJ, Meuffels DE, Reijman M, Simel DL, Bierma-Zeinstra SM: Does this patient with shoulder pain have rotator cuff disease?: The Rational Clinical Examination systematic review. JAMA 2013, 310(8):837-847.

13. Hanchard NC, Lenza M, Handoll HH, Takwoingi Y: Physical tests for shoulder impingements and local lesions of bursa, tendon or labrum that may accompany impingement. Cochrane Database Syst Rev 2013, 4:CD007427.

14. Hegedus EJ, Goode AP, Cook CE, Michener L, Myer CA, Myer DM, Wright AA: Which physical examination tests provide clinicians with the most value when examining the shoulder? Update of a systematic review with meta-analysis of individual tests. Br J Sports Med 2012, 46(14):964-978. 
15. De Wilde LF, Berghs BM, VandeVyver F, Schepens A, Verdonk RC: Glenohumeral relationship in the transverse plane of the body. J Shoulder Elbow Surg 2003, 12(3):260-267.

16. Weinberg A, Pichler W, Grechenig S, Tesch N, Heidari N, Grechenig W: Frequency of successful intra-articular puncture of the sternoclavicular joint: a cadaver study. Scand J Rheumatol 2009, 38(5):396-398.

17. Walton J, Mahajan S, Paxinos A, Marshall J, Bryant C, Shnier R, Quinn R, Murrell GA: Diagnostic values of tests for acromioclavicular joint pain. J Bone Joint Surg Am 2004, 86-A(4):807-812.

18. Wisniewski SJ, Smith J: Synovitis of the sternoclavicular joint: the role of ultrasound. Am J Phys Med Rehabil 2007, 86(4):322-323.

19. Sackett D, Haynes R, Guyatt G, Tugwell P: Clinical epidemiology: a basic science for clinical medicine. 3rd edition. Philadephia: Lippincott Williams and Wilkins; 2006.

20. Buckler WS: Primary generalized osteoarthritis with involvement of the sterno clavicular joints. Ann Phys Med 1955, 2(5):180-181.

21. Bremner RA: Monarticular, non-infective subacute arthritis of the sterno-clavlcular joint. J Bone Joint Surg (Br) 1959, 41-B:749-753.

22. Bonnin JG: Spontaneous subluxation of the sternoclavicular joint. Br Med J 1960, 2(5194):274-275.

23. Sadr B, Swann M: Spontaneous Dislocation of the Sterno-Clavicular Joint. Acta Orthop 1979, 50(3):269-274.

24. Van Tongel A, Valcke J, Piepers I, Verschueren T, De Wilde L: Relationship of the Medial Clavicular Head to the Manubrium in Normal and Symptomatic Degenerated Sternoclavicular Joints. J Bone Joint Surg Am 2014, 96(13):e109.

25. Inman VT, Saunders JB: Observations on the function of the clavicle. Calif Med 1946, 65(4):158-166.

26. Abbott LC, Lucas DB: The function of the clavicle; its surgical significance. Ann Surg 1954, 140(4):583-599.

27. Van Tongel A, Macdonald P, Leiter J, Pouliart N, Peeler J: A cadaveric study of the structural anatomy of the sternoclavicular joint. Clin Anat 2012, 25(7):903-910.

28. van Riet RP, Bell SN: Clinical evaluation of acromioclavicular joint pathology: sensitivity of a new test. J Shoulder Elbow Surg 2011, 20(1):73-76.

29. Pingsmann A, Patsalis T, Michiels I: Resection arthroplasty of the sternoclavicular joint for the treatment of primary degenerative sternoclavicular arthritis. J Bone Joint Surg (Br) 2002, 84(4):513-517.

30. Thongngarm T, McMurray RW: Osteoarthritis of the Sternoclavicular Joint. J Clin Rheumatol 2000, 6(5):269-271.

31. Jurik AG: Imaging of the Sternocostoclavicular region. Berlin Heidelberg New York: Springer; 2007.

\section{doi:10.1186/1471-2474-15-421}

Cite this article as: Van Tongel et al:: Diagnostic value of active protraction and retraction for sternoclavicular joint pain. BMC Musculoskeletal Disorders 2014 15:421.

\section{Submit your next manuscript to BioMed Central and take full advantage of:}

- Convenient online submission

- Thorough peer review

- No space constraints or color figure charges

- Immediate publication on acceptance

- Inclusion in PubMed, CAS, Scopus and Google Scholar

- Research which is freely available for redistribution 